\title{
MOTORCYCLE OWNERSHIP ASSESSMENT AND ESTIMATION IN MAKURDi, NORTH CENTRAL, NigERIA: A MULTINOMIAL LOGIT MODEL APPROACH
}

\author{
K. Gbagir ${ }^{1}$, J. E. Etu ${ }^{2}$ and O. J. Oyedepo ${ }^{3}$ \\ 1,2,3 Department of Civil Engineering, Federal University of Technology, PMB 704, Akure Ondo State, Nigeria \\ Date received: 31/05/2018, Date accepted: 10/08/2018 \\ Corresponding author's email: etujaphetheromietse@gmail.com
}

\begin{abstract}
With the rapid rise in problems associated with use of motorcycles as alternative means to inadequate public transportation, this study seeks to identify household factors influencing motorcycle ownership in Makurdi. The study estimates the influence of the various household factors identified and a model for predicting motorcycle ownership is developed for the study area. Data were collected via a questionnaire survey of 1412 households in the study area. The survey revealed that the number of motorcycles owned per household in the low density zone was 0.67 while that for the medium and high density zones was 0.62 and 0.79 respectively. The multinomial logit model developed predicted that $67 \%$ of households owned motorcycles as compared to $71 \%$ observed from survey data. Severity applications of the model to test the effects of changing economic situations on motorcycle ownership showed that residents of the study area are more disposed to owning motorcycles in periods of recession than periods of economic boom. The study gives an understanding of motorcycle growth pattern and ownership characteristics in the study area and will therefore serve as a relevant input for planning, regulation and control of motorcycle activities in the study area.
\end{abstract}

Copyright (O) 2018 UNIMAS Publisher. This is an open access article distributed under the Creative Commons Attribution-NonCommercial-ShareAlike 4.0 International License which permits unrestricted use, distribution, and reproduction in any medium, provided the original work is properly cited.

Keywords: Motorcycle ownership; multinomial model; household factors

\subsection{INTRODUCTION}

Rapid rise in urban population growth, coupled with drop in crude oil prices and limited financial resources available for investment in urban infrastructure has generated severe transport problems in oil producing developing countries such as Nigeria. Cities of such countries experience continuous increase in transport demand without corresponding supply of infrastructures to meet these demands. With the laxity being experienced in the supply of transport infrastructure occasioned by grossly inadequate funding for transportation improvements by government and relevant transport agencies, residents have been forced to develop creative solutions to address daily travel needs. This search for alternatives has led to the proliferation of non-conventional modes of public transport, initially provided by minibuses and shared taxi/vans, and more recently by commercial motorcycles.

Kumar [1] stated that these para transit modes have become the dominant form of public transport, asserting however that they also present clear disadvantages from a public welfare perspective in terms of the negative externalities generated (crimes, noise, safety, pollution etc). Gbadamosi [2] stated that motorcycles have constituted a major proportion of modal choice of intra-city trips for commuters in Nigerian cities since the late 80 's. Studies have revealed that the use of motorcycles offers many advantages such as better accessibility to different areas, ease of maintenance, relative cheapness of its use, curbing loss of economic man-hours, lateness to work, and other challenges associated with traffic jam. However, the continuous rise in its use has resulted in problems such as: accidents, pollution, high fares in relation to quality of service provided by the operators, and the nuisance often created by operators for traffic control and management in cities. It is therefore important to develop policies that provide a systematic basis for the operation of motorcycles in these cities to maximize its inherent advantages.

Sinha [3] stated that it is important to understand and predict consumer preferences regarding vehicle 
ownership and use as it will help in managing the consequent impacts on both transportation, land-use planning and the relationship to energy consumption, environment and health. The decision to own a first or additional vehicle can be based on a variety of factors, with commonly cited reasons including household location, workplace location, lifestyle commitments and personal status. Coupled with these factors is whether the household has sufficient income to purchase, maintain and accommodate the vehicle [4]. In this study, analysis of the motorcycle operating conditions in Makurdi Metropolis in North Central Nigeria was carried out, significant socio-economic, land use and socio-economic factors affecting the ownership of motorcycles were identified, and predictive models for estimating the number of motorcycles owned were developed. It is expected that the outcomes of this study will help in formulating transportation plans that will help reduce the problems associated with the use of motorcycles in this city thereby maximizing its inherent advantages.

\subsection{PROBLEMS OF MOTORCYCLE OPERATIONS IN NIGERIA}

The operation of motorcycles in Nigeria has been marred with a variety of problems. The operation of motorcycles particularly in urban areas has generated a lot of controversies despite the flexibility, doorto-door, speed, employment and income generating capacity of the mode. Akogun [5] observed that the problem with commercial motorcyclists is not only that of recklessness and non-adherence to traffic regulations, but that many of them have been accused of indulging in criminal activities. In an assessment of the crime occurrence in Nigerian cities, Chawki [6] discovered that some commercial motorcyclists are involved in crime such as snatching of handbags and phones, duping (419) of not only their passengers but pedestrians. He stated that of all these criminal activities, duping of people (419) is most common among commercial motorcycle riders and is a major challenge. This was also corroborated by Pius [7] who identified some of the crimes to include kidnapping, rape, murder, armed robbery and the unlawful possession of dangerous weapons.

Some commercial motorcyclists also engage in various acts of kidnapping both their passengers and other innocent members of society [8]. Use of motorcycles has also become a useful resource for politicians to rig elections. It has been observerd that some commercial motorcyclists are contracted by politicians to steal ballot boxes and other materials to aid in rigging elections [9].

A study at the Obafemi Awolowo Teaching Hospital, Ile-Ife, Nigeria, identified the use of personal protective equipment (PPE) to be practically non-existent among okada riders thereby leading to many fatal accidents with severe injuries [10]. These can be attributed to human error arising from recklessness, poor driving habit, excessive speed, and alcoholism. Other issues include poor state of the road, poor road traffic law enforcement and endemic urban public transportation system problems [11].

\subsection{BACKGROUND: PREVIOUS STUDIES}

Some motorcycle related studies have been carried out in Nigeria. A study on socio-demographic characteristics on commercial motorcycle riders in Akure metropolis was carried out [12]. Those findings show that majority of them have primary school leaving certificate and are apprentices in different trades. The study advocated implementation of stringent traffic enforcement measures that will encourage good driving behaviour. An assessment of socio-economic profiles of motorcycle operators, the characteristics of public motorcycle operations and the impact of motor bikes on passengers especially in terms of fares and safety in Ibadan, South West Nigeria has been conducted [13]. The factors affecting the daily profits of commercial motorcycle operators in Akure, the capital of Ondo State, South West Nigeria has also been studied [14]. A study by Musilimu and Oluwole [15] examined the operations and safety awareness of motorcycles operators in major urban centres in Osun State, namely Osogbo, Ilesa and Iwo. They realised $84 \%$ of motorcycle operators were under 40 years of age. Furthermore, they stated that unruly behaviour of commercial motorcyclists on urban roads was due to inadequate training and illegal possession of driving license as well as the inability of the police to enforce traffic rules and regulations. 
Predictive models have been developed to determine factors having influence on motorcycle ownership and use in Nigeria. A study evaluating the determinants of earnings among commercial motorcycle operators in Kwara State, Nigeria, discovered that the strong determinants of earnings include age of respondents, average fare charged per trip, location, and license holding [16]. Education was not a significant determinant, implying that the position of Human Capital Theory in terms of earnings of the employed and self-employed does not hold in the informal transport sub-sector. Oyedepo and Etu [17] examined factors which affect motorcycle ownership in Akure metropolis. The study showed that a unit increase in both the average monthly income and academic qualification of household head will lead to a reduction in the likelihood of owning a motorcycle by 1.66 times and 2.17 times respectively, while a unit increase in the number of household members will increase the likelihood of owning a motorcycle.

The reviewed studies have been able to assess and identify factors affecting motorcycle ownership and operation in different cities in Nigeria with none in Makurdi. However, Makurdi as an urban city has its own peculiarities in terms of factors affecting motorcycle ownership characteristics. As such, this study seeks to fill a research gap by identifying factors affecting motorcycle ownership in Makurdi based on the unique characteristics of residents in the city. The study also seeks to develop predictive models that can be used to estimate the specific quantity of motorcycle ownership in the study area. Severity analysis will be carried out to determine changes in ownership during periods of economic boom and recession.

\subsection{METHODOLOGY}

\subsection{DATA COLLECTION}

Data for this study were collected by dividing the study area into three population density zones: Low, Medium and High Density. Figure 1 shows the study area. A survey questionnaire was used in collecting information on socio-economic and motorcycle ownership characteristics from households in the study area. A total of 1412 households were sampled from all the zones in the study area. Data obtained from the survey were coded, inputted and analysed using SPSS 22 and Microsoft Excel 2016.

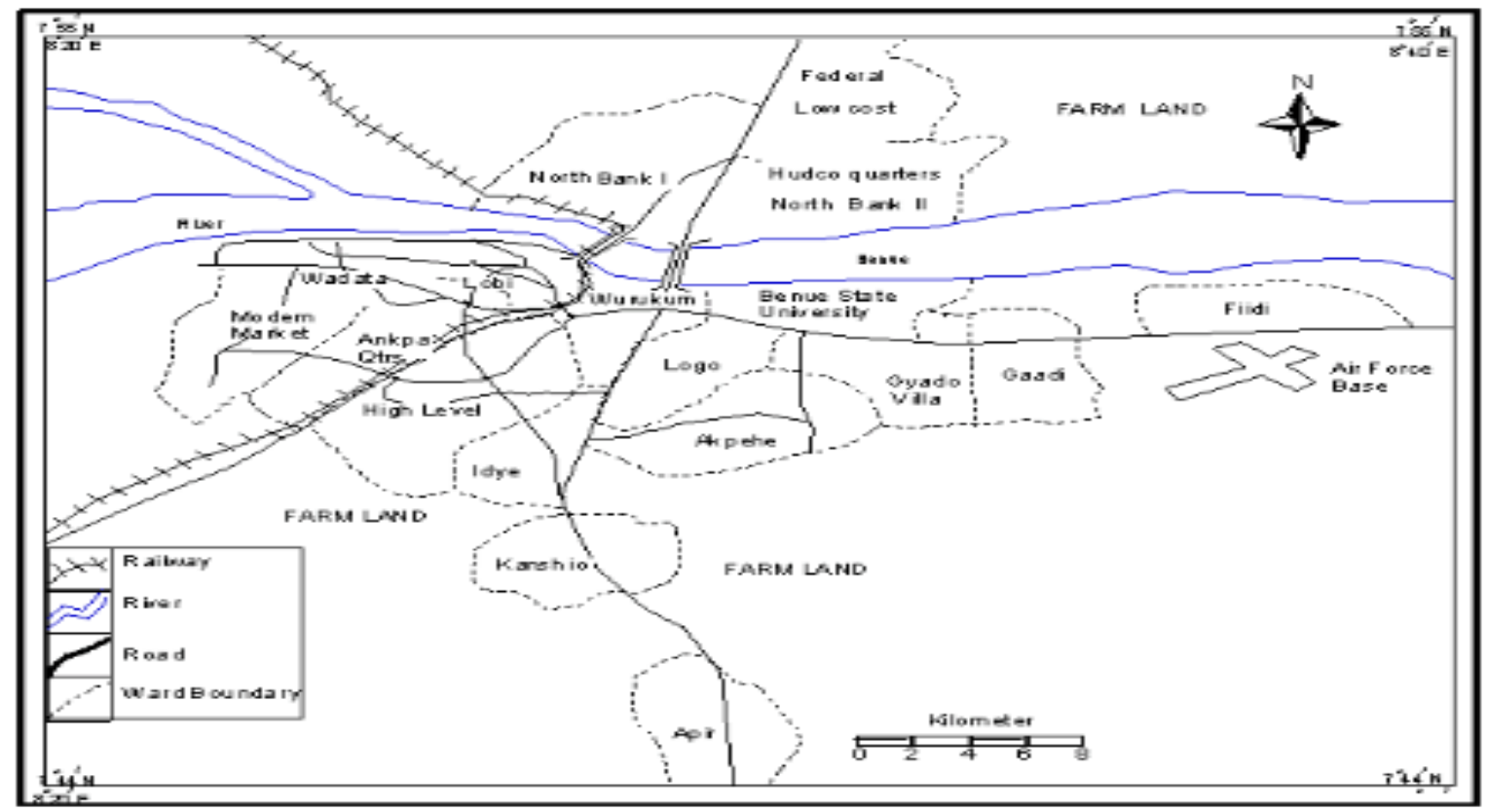

Figure 1 Makurdi road network and landuse map 


\subsection{DATA ANALYSIS AND MODELLING FRAMEWORK}

SPSS 22 and Microsoft Excel were used for statistical analysis. The Multinomial Logit (MNL) model was used to investigate the relationships that exist between household characteristics and motorcycle ownership (zero, one, two and greater than two motorcycles) in the city of Makurdi, Benue State. It was also used in determining the proportion of the different motorcycle ownership categories in the study area. The MNL is based on the micro-economic concept of utility maximisation and hence presupposes that a household prefers to own a certain number of motorcycles on the basis that it provides the most utility in the economic sense. The model is used to estimate the utility provided by each ownership category in the study area using Equation 1:

$$
\mathrm{U}_{\mathrm{m}}=\alpha_{\mathrm{m}}+\alpha_{1} \mathrm{Z}_{1}+\alpha_{2} \mathrm{Z}_{2}+\ldots \ldots \ldots \ldots \alpha_{\mathrm{n}} \mathrm{Z}_{\mathrm{n}}
$$

where $U_{m}$ is the utility provided by ownership category $m, \alpha_{m}$ is the category predicted parameter while $\alpha_{1}-\alpha_{n}$ and $Z_{1}-Z_{n}$ are the model coefficients determined by the model.

With the utilities computed, the probabilities of a resident owning a certain number of motorcycles (zero, one, two and greater than two motorcycles) were computed using Equation 2 or 3:

$$
\begin{aligned}
& \mathrm{P}_{\mathrm{m}}=\frac{\exp \left(\alpha_{\mathrm{m}}+\alpha_{1} \mathrm{Z}_{1}\right)}{\sum \exp \left(\alpha_{\mathrm{m}}+\alpha_{1} \mathrm{Z}_{1}\right)} \\
& \mathrm{P}_{\mathrm{m}}=\frac{\exp \left(\mathrm{U}_{\mathrm{m}}\right)}{\sum\left(\exp \left(\mathrm{U}_{\mathrm{m}}\right)\right)}
\end{aligned}
$$

Where $\mathrm{P}_{\mathrm{m}}$ is the probability that a household owns m number of motorcycles and $\Sigma\left(\exp \left(\mathrm{U}_{\mathrm{m}}\right)\right)$ is the summation of index utilities of the different categories. The probability of motorcycle ownership is restricted to lie between zero and one. One ownership category is chosen as the reference category, typically the first, the last or the value with the lowest or the highest frequency. For this study, the 0motorcycle ownership category was chosen as the reference category.

\subsection{RESULTS AND ANALYSIS}

\subsection{SURVEY RESULTS}

Descriptive statistics of the data obtained from the household questionnaire survey are given in this section. Number of questionnaires returned from the survey across the three zones is shown in Figure 2. Expectedly, most of the questionnaires returned were from the high density zone (715) while the number decreases with decrease in land use density to 472 and 225 for medium and low density zones respectively. The questionnaire survey results show that a total of 1008 respondents owned motorcycles across the zones. 150 of these respondents representing 15\% were from the Low Density Zone, 293 representing 29\% were from the Medium Density Zone while 565 representing 56\% were from the High Density Zone. This is shown in Figure 3. The results show that number of motorcycles owned increases with increasing land use density. 


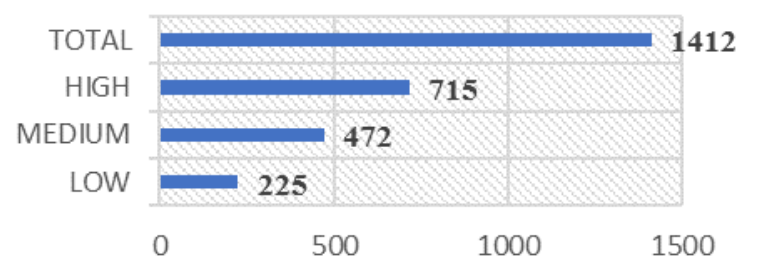

Figure 2 Number of survey questionnaires returned

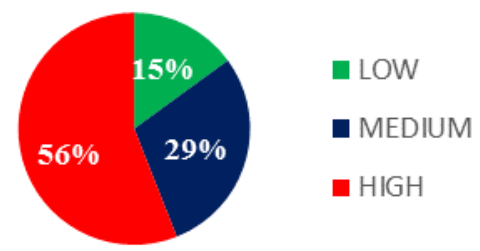

Figure 3 Number of motorcycles owned across the zones

Results in Figure 4 also show that the number of motorcycles owned per household is 0.67 in the low density zone, 0.62 in the medium density zone, and 0.79 in the high density zone. Figure 5 reveals that $49 \%$ of the households in the study area own 1 motorcycle, $15 \%$ own 2 motorcycles while about $7 \%$ own more than 2 motorcycles.

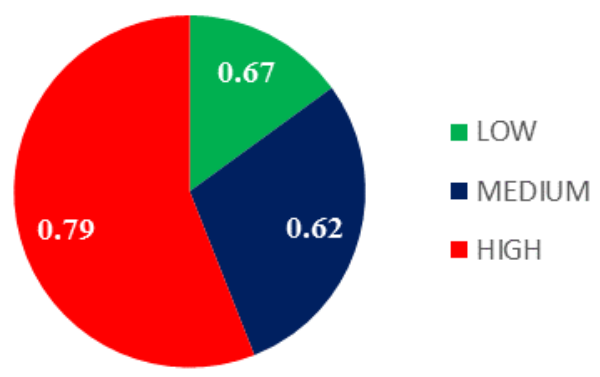

Figure 4 Motorcycle ownership per household across the zones

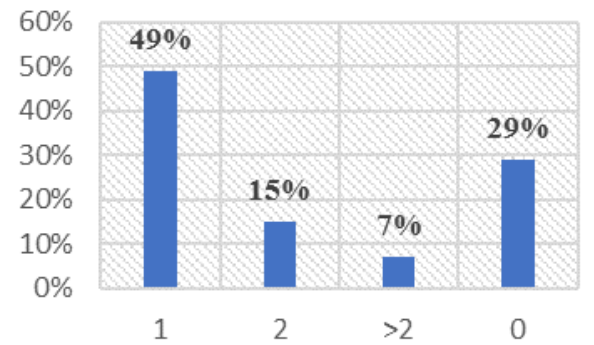

Figure 5 Motorcycle ownership per category across the zones

A depiction of the variation in academic qualification with motorcycle ownership in the study area is given in Figure 6 with aggregate data from the three zones. From the figure, it can be seen that most of the motorcycle owners were of the NCE/OND and Secondary School academic qualifications. 


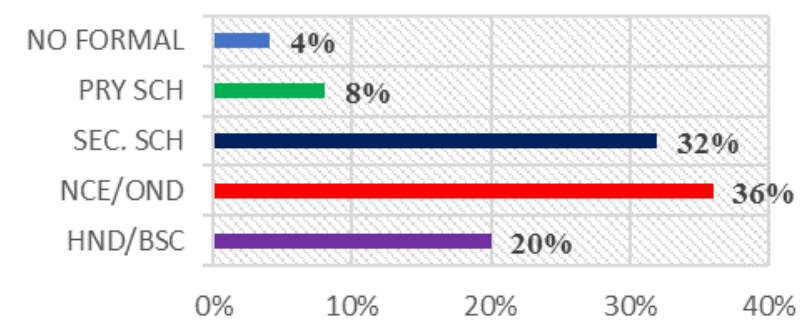

Figure 6 Educational qualification of household respondents

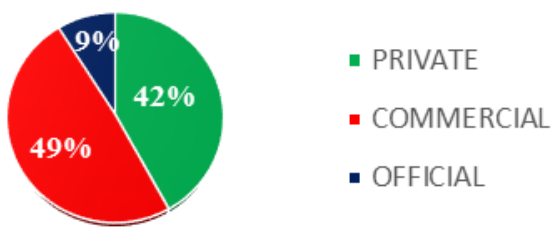

Figure 7 Use of motorcycle across the zones

An aggregate of the motorcycle use data from the survey across the three zones is shown in Figure 7 . It shows an almost even split between commercial and private purposes at $49 \%$ and $42 \%$ respectively. This shows that most households possess motorcycles mostly for either commercial or private purposes. Those who possess their motorcycle for official purposes were just $9 \%$ of the total number of respondents who owned motorcycles. The results also imply that the use to which a motorcycle is put tends towards commercial as the land use density increases.

The number of members per household visited across the zones is shown in Figure 8. The number of household members increased with increase in population density. This could be because of relatively cheaper cost of rent in high density zones.

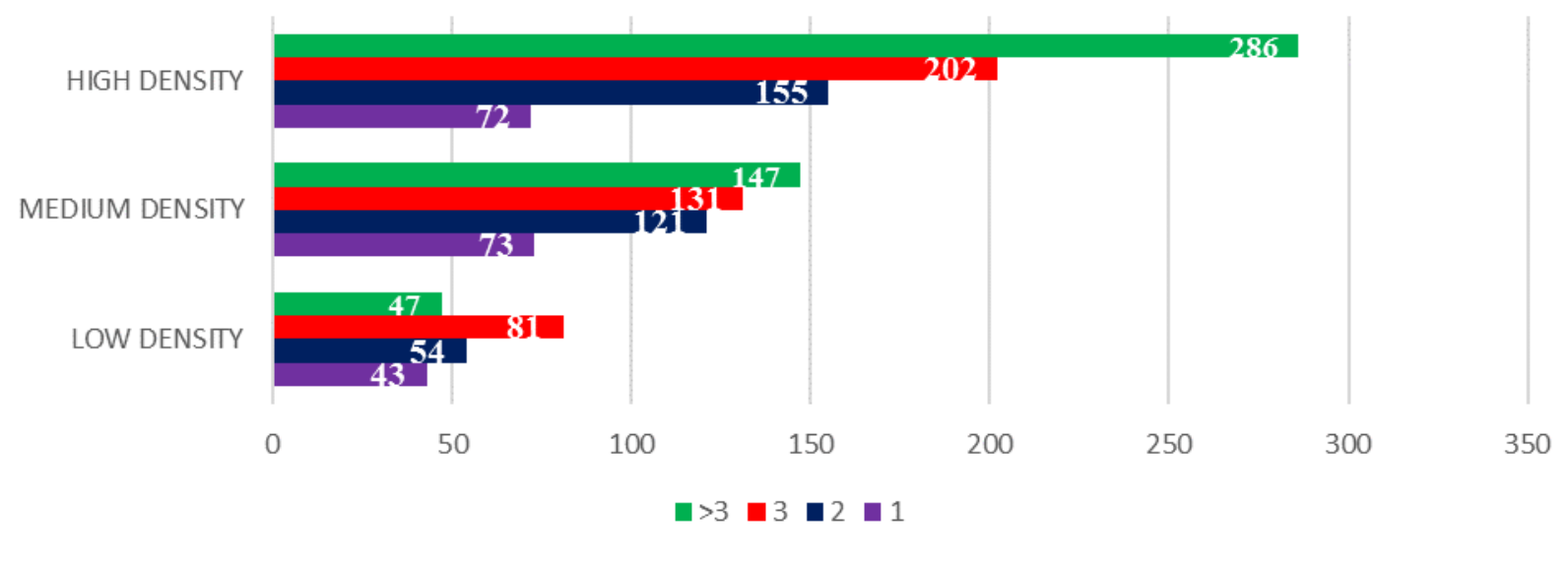

Figure 8 Number of household members across the study area

The number of employed household members across the zone is as shown in Figure 9 which shows that $33 \%$ of the employed household members across the study area reside in the low density zone, $43 \%$ in the high density zone, and $24 \%$ in the medium density zone. 


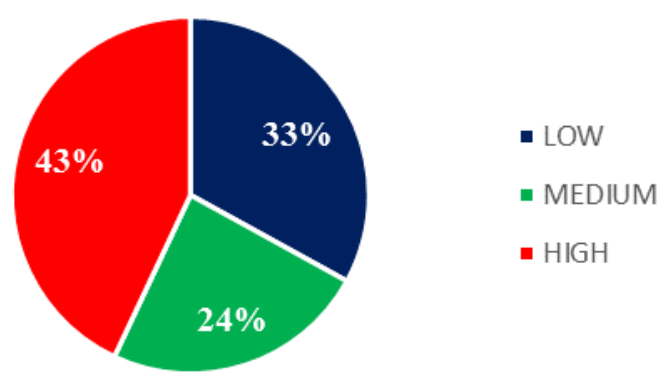

Figure 9 Number of employed household members across the study area

\subsection{MODELLING RESULTS}

Table 1 shows the variables used in developing the model and their coding.

Table 1 Variables and their coding

\begin{tabular}{|c|c|c|c|}
\hline S/No & Variable Type & Variable Name & Variable Code \\
\hline 1 & Dependent variable & $\begin{array}{c}\text { Number of motorcycles } \\
\text { No Motorcycle } \\
\text { One Motorcycle } \\
\text { Two motorcycles } \\
\text { >Two Motorcycles }\end{array}$ & $\begin{array}{l}N_{M} \\
N_{M 0} \\
N_{M 1} \\
N_{M 2} \\
N_{M>2}\end{array}$ \\
\hline 2 & & $\begin{array}{c}\text { Use of Motorcycle } \\
\text { Private } \\
\text { Commercial } \\
\text { Official }\end{array}$ & $\begin{array}{l}U \\
U_{1} \\
U_{2} \\
U_{3}\end{array}$ \\
\hline 3 & Independent variables & $\begin{array}{c}\text { Average Monthly Income } \\
<\$ 15,000 \\
\$ 15,000-\$ 25,000 \\
\$ 25,000-\$ 36,000 \\
\$ 36,000-\$ 45,000 \\
>\$ 45,000\end{array}$ & $\begin{array}{l}I \\
I_{1} \\
I_{2} \\
I_{3} \\
I_{4} \\
I_{5}\end{array}$ \\
\hline $\begin{array}{l}4 \\
5 \\
6\end{array}$ & & $\begin{array}{c}\text { Academic Qualification } \\
\text { Household Members } \\
\text { Employed Household Members }\end{array}$ & $\begin{array}{l}A_{Q} \\
H_{N} \\
E_{N}\end{array}$ \\
\hline
\end{tabular}

Using aggregate data from the three zones, a predictive model which can be used to predict household motorcycle ownership was developed for Makurdi metropolis. The model fitting information in Table 2 shows that the model developed is significant at the $95 \%$ confidence level (with Sig. $=0.00<0.05$ ) and is thereby accepted for predicting motorcycle ownership in the metropolis.

Table 2 Model fitting information

\begin{tabular}{ccccc}
\hline Model & Model Fitting Criteria & \multicolumn{3}{c}{ Likelihood Ratio Tests } \\
& -2Log Likelihood & Chi-Square & df & Sig. \\
\hline Intercept Only & 256.155 & & & \\
Final & 101.263 & 154.892 & 30 & .001 \\
\hline
\end{tabular}

The parameter estimates of statistically significant variables for the aggregate model for the metropolis are shown in Table 3. 
Considering the $\mathrm{B}$ values from the parameter estimates in Table 3 we have the model equations as follows:

For $>2$ motorcycles category

$$
N_{m>2}=0.577-0.965 E_{N}-0.117 A_{Q}-0.986 I_{5}
$$

This shows that only the number of employed household members $\left(\mathrm{E}_{\mathrm{N}}\right)$, academic qualification of

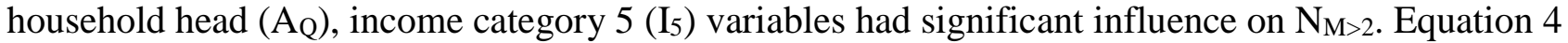
shows that $E_{N}, A_{Q}$, and $I_{5}$ have negative influence on $\mathrm{N}_{\mathrm{M}>2}$. The equation implies that a unit change in any of $E_{N}, A_{Q}$, and $I_{5}$ reduces the odds of owning greater than 2 motorcycles by $0.965,0.117$ and 0.986 times respectively.

Table 3 Parameter estimates for aggregate model

\begin{tabular}{ccccc}
\hline $\mathrm{N}_{\mathrm{M}}$ & $\begin{array}{c}\text { Independent } \\
\text { Variables }\end{array}$ & $\mathrm{B}$ & Std. Error & Sig. \\
\hline \multirow{4}{*}{$>2$} & Intercept & 0.577 & 2.435 & 0.000 \\
& $E_{N}$ & -0.965 & 1.872 & 0.050 \\
& $A_{Q}$ & -0.117 & 2.176 & 0.020 \\
& $I_{5}$ & -0.986 & 3.221 & 0.010 \\
& & & & \\
& Intercept & 1.076 & 2.222 & 0.010 \\
& $E_{N}$ & -0.532 & 2.068 & 0.010 \\
& $I_{1}$ & -1.231 & 1.571 & 0.003 \\
& $I_{3}$ & 0.524 & 1.623 & 0.000 \\
& $A_{Q}$ & -1.523 & 1.458 & 0.000 \\
& $H_{N}$ & 0.816 & 1.767 & 0.002 \\
& & & & \\
& & & & \\
& Intercept & 1.311 & 2.765 & 0.000 \\
& $U_{2}$ & 0.124 & 2.121 & 0.007 \\
& $E_{N}$ & -0.310 & 2.021 & 0.001 \\
& $I_{1}$ & 0.621 & 1.001 & 0.005 \\
& $A_{Q}$ & -1.737 & 1.067 & 0.000 \\
& $H_{N}$ & 0.325 & 1.523 & 0.000 \\
\hline
\end{tabular}

For 2 motorcycles category

$$
N_{m 22}=1.076-0.532 E_{N}-1.231 I_{1}+0.524 I_{a}-1.523 A_{Q}+0.816 H_{N}
$$

The model estimates from equation 5 shows that $E_{N}$ and $I_{1}$ and $A_{Q}$ had a negative influence on $N_{M 2}$, and the extent of this influence shows that a unit change in $\mathrm{E}_{\mathrm{N}}, \mathrm{A}_{\mathrm{Q}}$ and household with income category $1, \mathrm{I}_{1}$ reduces the likelihood of owning 2 motorcycles by $0.532,1.523$ and 1.231 respectively. However, $\mathrm{I}_{3}$ and $\mathrm{H}_{\mathrm{N}}$ have positive relationship on $\mathrm{N}_{\mathrm{M} 2}$, showing that the likelihood of owning 2 motorcycles in the study area is increased by 0.524 times if the household is of income category 3 and 0.816 times with a unit change in number of household members.

For 1 motorcycle category

$$
N_{m 1}=1.311+0.124 U_{2}-0.310 E_{N}+0.621 I_{1}-1.737 A_{\varphi}+0.325 H_{W}
$$

The likelihood of owning 1 motorcycle is affected by the number of employed household members $\left(\mathrm{E}_{\mathrm{N}}\right)$, academic qualification of household head $\left(\mathrm{A}_{\mathrm{Q}}\right)$, income category $1\left(\mathrm{I}_{1}\right)$, type of use of motorcycle $\left(\mathrm{U}_{2}\right)$ and number of household members $\left(\mathrm{H}_{\mathrm{N}}\right)$. From Equation 6, $\mathrm{E}_{\mathrm{N}}$ and $\mathrm{A}_{\mathrm{Q}}$ both have a negative influence on $\mathrm{N}_{\mathrm{M} 1}$ while $\mathrm{I}_{1}, \mathrm{U}_{1}$ and $\mathrm{H}_{\mathrm{N}}$ have a positive influence on it. The model implies that a unit change in $E_{N}$ and $A_{Q}$ reduces the likelihood of owning 1 motorcycle by 0.310 and 1.737 respectively 
while a unit change in $\mathrm{U}_{1}, \mathrm{I}_{1}$ and $\mathrm{H}_{\mathrm{N}}$ increases the likelihood of possessing 1 motorcycle by $0.124,0.621$ and 0.325 times respectively.

Probability Estimation of Ownership Categories

From equation 4-6 the estimated utilities are 1.491, -0.870 and 0.334 for $>2,2$ and 1 motorcycle ownership category respectively.

With the utility estimates, we proceed to calculate the probability of owning household motorcycle across the study area as follows:

$$
\begin{aligned}
& p\left(N_{M>2}\right)=\frac{e^{(-1.491)}}{e^{0}+e^{(-1.491)}+e^{(-0.870)}+e^{0.334}}=0.074046 \\
& p\left(N_{M 2}\right)=\frac{e^{(-0.870)}}{e^{0}+e^{(-1.491)}+e^{(-0.870)}+e^{0.334}}=0.137783 \\
& p\left(N_{M 1}\right)=\frac{e^{0.334}}{e^{0}+e^{(-1.491)}+e^{(-0.870)}+e^{0.334}}=0.459292 \\
& p\left(N_{M 0}\right)=\frac{e^{0}}{e^{0}+e^{(-1.491)}+e^{(-0.870)}+e^{0.334}}=0.328877
\end{aligned}
$$

Therefore, the model predicts that $46 \%$ of the households in the study area will own 1 motorcycle, $14 \%$ will own 2 motorcycles while about 7\% own greater than 2 motorcycles. The estimates also show that $33 \%$ of the households own 0 motorcycles. Summing of the probability of motorcycle owning households shows that $67 \%$ of household in the study area own motorcycles. The observed data from the questionnaire show an ownership rate of $71 \%$. The relative closeness of the ownership rate predicted by the model and that observed from field survey coupled with high R-square values as seen in Table 4 shows that the dependent variable has been well explained by the independent variables and as such validates the model.

Table 4 Model R-square values

\begin{tabular}{lc}
\hline Cox and Snell & .850 \\
Nagelkerke & .783 \\
Mcfadden & .704 \\
\hline
\end{tabular}

\subsection{SEVERITY APPLICATION OF THE HOUSEHOLD MOTORCYCLE OWNERSHIP MODEL}

Sensitivity analysis was carried out to test a number of policies and to measure their effects on motorcycle ownership in Makurdi metropolis (Cirillo and Liu, 2013). The following scenarios were tested:

Scenario 1: A season of economic boom and low mortality rate bringing about a $50 \%$ increase in income, number of employed household members and number of household members.

The model for scenario 1 predicts

- $57 \%$ of the households in the study area will own 1 motorcycle

- $10 \%$ will own 2 motorcycles

- $3 \%$ will own greater than 2 motorcycles

- $30 \%$ of the households will own 0 motorcycles. 
Scenario 2: A season of economic recession and high mortality rate bringing about a $50 \%$ reduction in income, number of employed household members and number of household members.

The model for scenario 1 predicts

- $32 \%$ of the households in the study area will own 1 motorcycle

- $17 \%$ will own 2 motorcycles

- $19 \%$ will own greater than 2 motorcycles

- $32 \%$ of the households will own 0 motorcycles.

Table 5 Sensitivity application of the motorcycle ownership model

\begin{tabular}{cccc}
\hline Motorcycle Ownership & Current & Scenario1 & Scenario2 \\
\hline $\mathrm{N}_{\mathrm{M} 0}$ & $466(33 \%)$ & $423(30 \%)$ & $452(32 \%)$ \\
$\mathrm{N}_{\mathrm{M} 1}$ & $650(46 \%)$ & $805(57 \%)$ & $452(32 \%)$ \\
$\mathrm{N}_{\mathrm{M} 2}$ & $198(14 \%)$ & $141(10 \%)$ & $240(17 \%)$ \\
$\mathrm{N}_{\mathrm{M}>2}$ & $99(7 \%)$ & $42(3 \%)$ & $268(19 \%)$ \\
Number of households & 1412 & 1412 & 1412 \\
Total Number of Motorcycles Owning households & 946 & 988 & 960 \\
Total Number of motorcycles owned & 1343 & 1213 & 1736 \\
Average number of Motorcycles per household & 0.95 & 0.86 & 1.23 \\
Difference in Motorcycles owned & - & -130 & +393 \\
$\%$ Difference & - & $-9.7 \%$ & $+23 \%$ \\
\hline
\end{tabular}

Table 5 shows the results that the application of the various effects on the model yields. The results show that there will be a decrease in number of motorcycles owned when the effects in scenario 1 are considered whereas the number of household motorcycles owned will be increased when the effects in scenario 2 are applied. In the current conditions, the aggregate model estimates that 1343 motorcycles will be owned in the zone while 1213 and 1736 motorcycles will be owned considering Scenario 1 and Scenario 2 respectively. This shows that there will be about $10 \%$ decrease in the number of household motorcycles owned in scenario 1 while there will be $23 \%$ increase in the number of household motorcycles owned in scenario 2.

The model predicts an ownership rate of 0.95 motorcycles per household at the current condition. However, this is reduced to 0.86 in scenario 1 while it is increased to 1.23 in scenario 2 .

From the foregoing, it could be deduced that people are more disposed to owning motorcycles in periods of recession when the economic conditions are not favourable whereas in periods of economic boom with favourable economic conditions they are less likely to own motorcycles. This means that high income earners will be more disposed to owning other vehicles than owning a motorcycle in the study area.

\subsection{CONCLUSIONS}

This study carried out an assessment of motorcycle ownership characteristics in Makurdi, Benue state in North Central Nigeria with a view to developing a predictive model that can be used in estimating motorcycle ownership based on the characteristics identified. The study area was divided into low, medium and high population density zones. Data were collected from these zones in the study area via a household questionnaire survey. Results obtained from field survey were analysed and Multinomial Logit Models were developed using SPSS 22. Results from the questionnaire survey showed that the number of motorcycles owned per household in the low density zone is 0.67 while that for the medium density zone is 0.62 . The number of motorcycles owed per household in the high density zone is 0.79 . The Multinomial Logit model predicts that $67 \%$ of the household would own motorcycles as compared to $71 \%$ observed from the field survey. The relative closeness of the ownership rate predicted by the model and that observed from field survey coupled with high R-square values showed that the model 
was a good fit for the data obtained. Severity applications of the model to test the effects of changing economic situations on motorcycle ownership showed that residents of the study area are more disposed to owning motorcycles in periods of recession when the economic conditions are not favourable whereas in periods of economic boom with favourable economic conditions they will less likely own motorcycles. Since the motorcycle growth pattern and ownership characteristics has been understood, these study results will provide a basis for regulation and control of activities and operations of motorcycles in the study area.

\section{REFERENCES}

[1] Ajay Kumar (2011). Understanding the emerging role of motorcycles in African cities- A political economy perspective, SSATP Discussion paper, No. 13.

[2] Gbadamosi K. T. (2006). "The Emergence of Motorcycle in Urban Transportation in Nigeria and Its Implication on Traffic Safety", Association for European Transport and contributors

[3] Sinha, K.C. 2003. Sustainability and urban public transportation, Journal of Transportation Engineering 129(4): 331-341.

[4] Dargay, J. 2002. Determinants of Car Ownership in Rural and Urban Areas: A Pseudo-Panel Analysis, Transportation Research Part E: Logistics and Transportation Review 38(5): 351-366.

[5] Akogun K. (2008). Furore Over Helmet Law. This Day, January 1, 2008.

[6] Chawki M. (2009). Nigeria Tackles Advance Fee Fraud. Journal of Information. Retrieved April 15, 2009. From http://isuisse.ifrance.com/emma/base/impvic.html

[7] Pius C (2009). Okada Menace: Tricycle to the Rescue. Retrieved December 10, 2009 from http://bit.ly/8y5e9s

[8] Nwakwo P. Okorie C. and Onyekachi O. (2008). Kidnapping: Political and Economic Motive. Christian Bulletin. 18(4). 56-72.

[9] Effah, P. (2005). Why Kidnapping and Robbery? Nigeria Chronicles, November 16, 2009.

[10] Oluwadiya, K. S., Oginni, L. M., Olaseinde, A. A. and Fadiora, S. O. (2004). Motorcycle limb injuries in a developing country. West Africa Journal Medicine. 3(1):42-47.

[11] Oyesiku, O. K. (2012). Policy framework for urban motorcycle public transport system in Nigerian cities. Centre for Transport Studies, Olabisi Onabanjo University, Ago-Iwoye, Nigeria.

[12] Oyedepo Joseph O. (2014). Assessment of Socio-Demographic Characteristics of Commercial Motorcyclist in Akure, Nigeria.

[13] Adesanya, A. (1998). The use of Motorcycles for Public Transportation in Nigeria: The situation in Ibadan, NISER Monograph Series, No. 6.

[14] Fasakin, J. O. (2001). "Some factors affecting daily profits of Commercial Motorcycles in Akure, Nigeria" Transport Policy, 8(1): 63-69.

[15] Musilimu A. A. Oluwole A. (2014). The Level of Compliance of Commercial Motorcyclists to Traffic Rules on Urban Roads in South Western Nigeria. Journal of Educational and Social Research 4(3) 345-351

[16] Yakubu, Ahmed Taruwere (2012). Determinants of Earnings among Commercial Motorcycle Operators in Kwara State, Nigeria. International Journal of Economics and Management Sciences. 2(2), 11-17

[17] Oyedepo O. J., and Etu J. E. (2015). Binomial Logistic Regression Model of Household Motorcycle Ownership in Akure, Ondo State Nigeria. Journal of Transport Literature, 9(4), 40-44. 